\title{
Entre negro oscuro y moreno claro: discursos e identidades étnicas en niños y niñas afrodescendientes en contexto escolar en Bogotá
}

\begin{tabular}{c}
\hline Entre negro escuro e moreno claro: \\
discursos e identidades étnicas em \\
meninos e meninas afrodescendentes \\
em contexto escolar de Bogotá \\
\hline
\end{tabular}

\section{Between dark black and light brown: speeches and ethnic identities in children in school context of African descent in Bogota}

\author{
Sandra Soler Castillo ${ }^{1}$
}

\begin{abstract}
RESUMEN
A partir del análisis del discurso y la psicología social, este texto intenta comprender la manera como construyen las identidades étnicas niños y niñas afrodescendientes entre seis y doce años en contextos escolares en Bogotá. El objetivo es identificar los mecanismos discursivos que permiten conocer cómo se originan los procesos identitarios a partir de aceptación o negación de lo étnico, y que pueden llevar o incidir en procesos de adaptación, resistencia o negociación. Los hallazgos sugieren que los niños inician temprano su autoidentificación étnica a partir del color de la piel, en el que diferencian una amplia escala cromática, tendiente al blanquemiento. Tienen distinto grado de valoración étnica que va del orgullo al rechazo. En las relaciones interétnicas tienden a negar el conflicto o a minimizarlo y existe una tendencia a negarse a hablar de él. Identifican la causa del problema como un asunto de cantidad, en el que ellos son minoría en Bogotá. En las
\end{abstract}

${ }^{1}$ Doutora em Linguística e Comunicação pela Universidade de Barcelona, Espanha. Professora assistente da Universidade Distrital "Francisco José de Caldas" em Bogotá, Colômbia. E-mail: ssoler73@hotmail.com 
dinámicas interétnicas algunos aceptan los estereotipos que se les asignan; otros lo rechazan y otros se burlan de ellos.

Palabras-clave: discurso; identidades; autoidentificación; valoración.

\title{
RESUMO
}

A partir da análise do discurso e da psicologia social, esse texto tenta compreender a forma como constroem identidades étnico-raciais meninos e meninas afrodescendentes de seis a doze anos, em contextos escolares de Bogotá. O objetivo é identificar os mecanismos discursivos que permiten conhecer como se originam os processos identitários a partir da aceitação ou negação da etnicidade, o que pode levar a incidir sobre processos de adaptação, resistência ou negociação. Os achados sugerem que as crianças iniciam cedo sua autoidentificação étnico-racial a partir da cor da pele, na qual diferenciam uma ampla escala cromática, tendendo ao branqueamento. Eles apresentaram distintos graus de valoração étnico-racial, que vão do orgulho ao rechaço. Nas relações inter-raciais, tendem a negar o conflito ou a minimizá-lo e existe uma tendência à negação em falar sobre os conflitos. Identificam a causa do problema como um assunto de quantidade, sendo minoria em Bogotá. Nas dinâmicas interétnicas, alguns aceitam os estereótipos com que os assinalam, outros os repulsam e ainda outros caçoam deles.

Palavras-chave: discurso; identidades; autoidentificação; valoração.

\begin{abstract}
There is a felt need to understand the way ethnic identities are constructed by Afrodescendant boys and girls aged 6-12 in school contexts in Bogotá as there is little research in such specific context and topic in Colombia. This research report proposes a discourse analysis and social psychology approach to confront such problem. Thus this paper seeks to identify the discursive mechanisms that allow us to know how identity processes emerge from the acceptance or denial of ethnicity; mechanisms that may lead or have an effect on discursive adaptation, resistance or negotiation. Findings suggest that children begin early their ethnic self-identification from the color of the skin, whereby they differentiate a wide color range, tending towards whitening. Children have different degrees of ethnic appraisal that go from pride to rejection. In inter-ethnic relations, they tend to deny or minimize the conflict, and there is a tendency to avoid speaking about it. Children identify the cause of the problem as a quantitative issue, as they are minority in Bogotá. In inter-ethnic dynamics, some children accept the stereotypes assigned to them, others reject them, and others scoff at them.
\end{abstract}

Keywords: discourse; identities; self-identification; appraisal. 


\section{Introducción}

Hace ya algunos años, por la década de los años de 1990, comencé a trabajar con la comunidad indígena inga residente en Bogotá; realicé trabajo de campo visitando las escuelas bogotanas a las que asistían niños y niñas de esta comunidad con la preocupación por las interacciones establecidas en la escuela entre profesores y estudiantes y entre estudiantes entre sí. Me impactó en ese entonces lo que yo percibí como "sufrimiento" de los niños y niñas en la escuela. El hecho de no querer ser identificados como indígenas, de querer pasar desapercibidos, de no ser objeto de burlas por los compañeros o de exotismo por los profesores. Sin embargo, los objetivos de mi investigación eran otros y en ellos me centré (SOLER, 1999). Años después, comencé a trabajar con comunidades afrosdescendientes frente al tema del racismo. Analicé el contexto escolar pero desde la perspectiva de los textos escolares y la representación de indígenas y afrodescendientes (SOLER, 2008, SOLER PARDO, 2007). A partir de este trabajo, tuve la oportunidad de asesorar dos tesis de pregrado de estudiantes que querían analizar las interacciones étnicas en la escuela. Se trabajó con entrevistas semiestructuradas que las estudiantes realizaron y con diarios de campo (SANTIESTEBAN, 2005; MOLINA; VARGAS, 2009).

Dicho material volvió a despertar mi interés por las relaciones interétnicas en la escuela y por la manera como niños y niñas iban construyendo con el paso de los años sus identidades étnicas. Con el consentimiento de las estudiantes, retomo las entrevistas realizadas y presento aquí una aproximación a la comprensión de las identidades étnicas de niños y niñas afrodescendientes en el contexto escolar bogotano, no sin antes señalar las limitaciones de trabajar entrevistas no realizadas por mí, y de tratarse de entrevistas con niños y niñas en edades bastante tempranas ( 5 y 12 años). Las interpretaciones podrían parecer de alguna manera visiones desde los adultos; mi interés, sin embargo, se orienta más hacia un diálogo generacional en el que en la medida de lo posible, privilegiaré la voz de los niños y las niñas. Me aproximo a un análisis cualitativo de corte teoría fundada en el que el fin último no es revisar y comprobar teorías sobre las identidades, sino proponer algunos elementos teóricos y de discusión a partir de los datos, las voces de niños y niñas.

\section{Referentes teóricos de entrada}

Parto del supuesto del no agotamiento de las problemáticas en una única disciplina o ciencia y en consecuencia en la necesidad de ofrecer interpretaciones 
diversas que se complementen y contribuyan a percibir los fenómenos como hechos complejos.

\section{En torno al concepto de identidades}

Como señala Stuart Hall (1996) en la introducción del influyente texto Cuestiones de identidad cultural, "en los últimos años se registró una verdadera explosión discursiva en torno al concepto de identidad, al mismo tiempo que se lo sometía a una crítica rigurosa" (HALL, 1996, p. 13). No es el interés de estas líneas ahondar en la discusión, pero sí dejar claro cuál será el locus de enunciación de este trabajo, desde el punto de vista teórico y metodológico. Siguiendo a Hall, acepto que se trata de deconstruir el término identidad antes que de desecharlo totalmente. Por esta razón, no comenzaré por dar una definición a priori, sino por anotar algunas de las características de las identidades que asumiré.

Parto diciendo que, como en efecto se ha señalado hasta la saciedad, no hay identidades esenciales, inmutables o ahistóricas. Adhiero a la idea de identidades fragmentadas, en construcción y en tensión. Lo que permite un descentramiento de las preguntas por la identidad en las que, parafraseando a Hall, más que preguntarnos por un quién soy o de dónde vengo es preferible cuestionarse por aquello en lo que podríamos convertirnos, en cómo nos han representado a lo largo de la historia y cómo dicha representación influye en la manera como podríamos representarnos nosotros mismos (HALL, 1996, p. 18). Asumo en consecuencia que las identidades se construyen a partir de la relación con los otros, que son relacionales en el sentido que dan cuenta de prácticas de diferenciación y marcación de un nosotros con un "otros". Por esta razón, autores como Restrepo señalan la importancia de entender la identidad y la diferencia como dos caras de la misma moneda, aunque no con el mismo valor. Dicha relación está determinada por el poder, las jerarquías sociales, culturales y políticas. De allí que diferencia sea sinónimo de sometimiento, explotación o dominio (HALL, citado por RESTREPO, 2007, p. 27). Sin embargo, las identidades también son la arena en la que se disputan estas relaciones de poder, pues los sujetos negocian, rechazan o resisten. Para Hall, las identidades constituyen el punto de sutura entre la sujeción y la subjetivación:

Una identidad es un punto de sutura, de articulación, en un momento concreto entre: (1) los discursos y las prácticas que constituyen las locaciones sociales o posiciones de sujeto (mujer, joven, indígena, etc.) y (2) los procesos de producción de subjetividades que conducen a aceptar, modificar o rechazar estas locaciones o posicionamientos de sujeto (citado en RESTREPO 2007, p. 30). 
De allí que como señala Hall, un estudio sobre las identidades "no debe iniciarse con el sujeto sino como una descripción de los efectos de sutura, la afectación del enlace del sujeto con estructuras de sentido" (HALL, 1996, p. 20).

Asumo también que la construcción de las identidades se da en las prácticas y en especial a través del discurso. Entendido el discurso como una doble práctica: si bien ella misma es un hacer también a través de él se construyen realidades, como señala Escobar: "es una práctica constituyente de cualquier acción, relación, representación o disputa en el terreno de lo social" (HALL, 1996, p. 27). La entrada al discurso se da entonces, mediada por las relaciones de poder que gobiernan lo social, y en la que la cuestión de la identidad se convierte en un aspecto relevante para la consideración del agenciamiento.

\section{Las identidades sociales}

Hablar de identidades sociales permite ubicarlas en el campo de las relaciones interpersonales y descentrarlas del aspecto individual en el que generalmente se les ubica. La psicología social fue pionera en esta identificación. Henri Tajfel, a mediados de los años de 1970, comenzó a interesarse por el desarrollo de las identidades sociales en los individuos y lo explicó a partir de procesos psicosociales como la categorización y la valoración.

Para Tajfel, la identidad forma parte del autoconcepto que se deriva de la relación de la persona con ciertas categorías o grupos sociales. El autoconcepto lo define como una estructura cognitiva formada a partir de los procesos de categorización del sí mismo y de los otros, sobre la base de las similitudes y diferencias. Según este autor, la categorización es uno de los procesos fundamentales en la construcción de las identidades sociales: "la identidad social de una persona se halla relacionada con el conocimiento de su pertenencia a ciertos grupos sociales y con la significación emocional y valorativa que resulta de esta pertenencia" (citado en GARRIDO; ÁLVARO, 2007, p. 392). Pero la identidad social no sólo se limita a la pertenencia a grupos sociales, sino a procesos comparativos que realiza la persona entre los grupos a los que pertenece y los ajenos. De esta comparación surge un proceso de valoración que determinará la pertenecía y las relaciones que se tengan y puedan establecerse con esos grupos. La persona tenderá a permanecer en el grupo si éste contribuye de manera positiva a su identidad, de lo contrario, tenderá a dejarlo, si puede o es posible; si no, intentará cambiar la valoración de su grupo o cambiar la situación que origina la valoración negativa. 


\section{Las identidades étnicas}

Según la psicología social, existen de distintos tipos de identidades, entre ellas, la identidad étnica, referida al sentido de pertenencia a un grupo étnico y a la parte de los procesos emocionales, de acción y pensamiento que se derivan del reconocimiento de la propia etnicidad (SMITH, 2002, p. 72). Los psicólogos sociales distinguen además entre grupo étnico y etnicidad. El primero lo definen como aquel "que se distingue por tener ciertas características culturales comunes entre sí, pero diferentes a las de otros grupos humanos" (DUNCAN; POWEL, 1988, p. 19, citado en SMITH, 2002) y el segundo como el hecho concreto de nacer dentro de un grupo étnico particular, sin excluir la posibilidad de pertenecer a dos o más grupos étnicos. Mientras que la etnicidad es el "marcador" objetivo de la pertenencia a un colectivo étnico, la identidad étnica apunta al significado subjetivo de pertenecer a tal(es) grupo(s) étnico(s) (SMITH, 2002).

\section{Implicaciones metodológicas}

Lo expuesto orienta el establecimiento de marcos metodológicos enfocados a evitar las generalizaciones o homogenizaciones de los sujetos y los grupos. En ese sentido, es preferible optar por establecer singularidades, particularidades, y diferencias. Sin olvidar que es justamente aquí donde resulta peligroso el empleo de conceptos como identidad, que se relaciona con lo idéntico, lo semejante, lo igual. Ahora bien, si se adopta el supuesto de que las identidades no son esenciales sino construcciones, la metodología debe apuntar a mostrar cómo se da dicha construcción, cuáles son las trayectorias y tensiones históricas y en un momento particular, sin olvidarnos de las causas y los porqués de sus formaciones, lo cual permitiría poder hablar, por ejemplo, de los denominados esencialismos estratégicos, que obedecerían a razones políticas particulares de los grupos étnicos.

Por último, si las identidades son discursos y se construyen en el discurso, es allí donde interesa analizarlas. En la actualidad hay un auge por lo que se ha denominado el giro narrativo, el cual compartimos, pues como señala Bruner (1994, p. 694): “Al final nos convertimos en las narrativas autobiográficas a través de las cuales relatamos nuestras vidas". Trabajar con narrativas supone un reconocimiento del poder de la palabra oral, supone un sentido estético si se quiere, y en ningún caso, como lo señalara Jorge Larrosa en una charla informal en la Universidad Javeriana, un deseo morboso por el otro. Trabajar con narraciones parte del principio fundamental de que el otro es importante y de que tiene algo que contar que es igualmente importante, y quizá, lo más importante, que yo tengo el deseo de escucharlo. 


\section{Análisis}

El corpus lo constituyen 10 entrevistas realizadas a niños y niñas que asisten a programas de escolarización, desde jardines infantiles hasta colegios, públicos y privados, con el fin de estudiar la relación de los estudiantes afrodescendientes y los mestizos en la escuela. El rango etario va de los 5 a los 12 años. Se trata de dos series de entrevistas, una primera realizada en el 2005 por una estudiante que preparaba su trabajo de tesis de pregrado. Estas entrevistas se realizaron a niños y niñas de condiciones económicas bajas y medias; estudiantes de diversos planteles educativos algunos públicos otros privados. La segunda serie de entrevistas la constituyen cinco entrevistas realizadas en el 2007 por dos estudiantes de la Universidad Distrital. Las entrevistas se acompañaron de trabajo etnográfico y diarios de campos. En el caso de la segunda serie de entrevistas, las entrevistadoras realizaron sus prácticas en el colegio en el que estudiaban los niños y niñas, por lo que el grado de familiaridad con los y las entrevistados fue alto.

El análisis de las entrevistas pasa por identificar los procesos de categorización y valoración de los entrevistados, continúa con el análisis de lo que denominamos dinámicas discursivas, que dan cuenta de los procesos de identificación, conflicto o resistencia y termina ofreciendo algunas reflexiones teóricas sobre las identidades étnicas.

\section{La autoidentificación}

\section{Metonimia del color}

Los niños y las niñas entrevistados emplean diversas categorías étnicas para referirse a sí mismos. Sin embargo, hay una identificación temprana basada en la identificación física determinada por el color de la piel y otros rasgos como las facciones y el tipo de cabello. Esta primera identificación gobierna la categorización y podría describirse como un proceso metonímico en el que la raza se equipara al color de la piel, tal como la identificó Santiesteban en su monografía (2005). Así lo señalan varios de los niños: 

A: ¿La gente de tu raza?
B: sí, de mi raza, pues la gente de color...
A: ¿De qué color crees que eres?
B: Pues mírame...
A: te veo pero quiero que hagamos un ejercicio... si tuvieras que escoger, tú dirías que eres: Afrodescendiente, Moreno, Negro, Nigger, Otro, ¿Cuál?
B: Pues breve el ejercicio, porque soy negro, como mi mamá, mi papá $\mathrm{y}$ mis hermanos.

El niño no duda en identificar la raza con el color y, además, ante la pregunta de la entrevistadora, señala lo evidente de la respuesta en términos de los sentidos: se trata sólo de mirar para identificar el color. Sentido que luego se resalta al reiterar que su color es negro.

\section{La variación cromática}

Identificar el asunto racial como un problema de color, sin embargo, no significa que haya unicidad de criterios, los niños y las niñas entrevistados se identifican con una amplia gama de colores que van desde el negro oscuro al moreno claro, en el que la mayor parte de las veces, aunque no siempre, el negro oscuro adquiere connotaciones negativas y el moreno claro representa lo positivo y deseable. Clasificaciones que parecieran un rezago de la lógica de la sociedad de castas, establecida durante la colonia en la que las personas adquirían estatus social de acuerdo con los diversos matices de pigmentación de sus pieles.

\section{Soy negro}

Dentro de la variada amalgama de colores identificados por los y las entrevistadas, hay algunos que se identifican como negros. Este es el caso de Juan:

A: Hagamos un ejercicio: Si tuvieras que escoger, tú dirías que eres Afrodescendiente, Moreno, Negro, Nigger, ¿Otro?, ¿Cuál?

B: No sé, creo que soy negro, porque pues ese es mi color, ¿cierto?, además así me dice una gente cuando no se sabe mi nombre o a veces mis compañeros, pero a mí me gusta más que me digan negrito lindo (ríe).

De nuevo, Juan recurre al color de la piel para autoidentificarse. Se reconoce negro aceptando además la categorización externa que le es atribuida. 


\section{Soy un moreno bacano}

En la escala cromática que niños y niñas reconocen, algunos no se identifican como negros, sino como pertenecientes a un tono más claro. Este es el caso de Miguel:

A: Bueno, entonces respóndeme si tuvieras que elegir, tú dirías que eres: Afrodescendiente, Moreno, Negro, Nigger, ¿Otro?, ¿Cuál?

B: Yo soy un Moreno bacano (ríe)

\section{Casi cafés}

Otra denominación encontrada es a la que recurre Ronaldo, quien cuestiona el hecho de que los niños blancos no identifiquen las diferencias cromáticas:

A: ¿Y a él por qué lo estaban molestando? ¿Sabes?

B: ...

A: Porque él me dijo que unos niños... él estaba tranquilo y unos niños le habían empezado a decir negro. ¿No te dijo eso a ti?

B: No (gestual).

A: ¿Y tú por qué crees que le dijeron eso?

B: Porque como somos pues casi cafés entonces... entonces...

A: ¿Quiénes son casi cafés?

B: Es que como somos casi cafés le dijeron... nos dijieron.. a mí también me dicen negro.

\section{Moreno suavecito}

Una vez que niños y niñas se clasifican como morenos, ese parece ser el punto de partida para identificar otros colores, que simplemente irían aproximándose al blanco, el color no marcado, el color con rasgos positivos.

B: Si, o sea, no es igual al color de mi piel.

A: Y la gente que es.. ¿la gente que tiene el color de tu piel, cómo le llamas?

B: eh... moreno suavecito. 
A: Moreno suavecito... Por ejemplo tu tía aquí (señalo a la tía, que está presente) ¿cómo sería? ¿Qué dirías que es?...

B: Moreno oscurito.

A: O tus papás...

B: Mi papá es moreno oscurito y mi mamá es... como... casiclari... es como el color de piel de mi hermano. O sea, no sé muy bien como llamarlo.

A: ah... pero...

B: es como una... una... es más clarito.

A: Más clarito. Tu dirías que todos en tu casa son del mismo color de piel?

B: No.

A; No... ¿Todos son diferentes?

B: O sea, yo salí más o menos del mismo color de mi papá.

A: Que es más claro que el de tu mamá ¿o más oscuro?

B: No, es más oscuro que el de mi mamá. Y mi hermanito sí salió con el... con el color de la piel de mi mamá.

\section{Otras formas de categorización de la pertenencia}

Frente a categorizaciones como afrodescendiente, niños y niñas no la utilizan con frecuencia. Sólo en los casos en que lo utilizan las entrevistadoras. Reconocen que se trata de una denominación externa proveniente del contexto escolar o familiar; en su mayoría no han asimilado en concepto, no saben exactamente a qué refiere excepto que remite al pasado. Obsérvese la siguiente secuencia en la que Manuel no entiende bien lo que la entrevistadora le pregunta, y para estar seguro la interroga:

A: ¿Hay más niños afros en tu salón?

B: ¿Cómo decís?, ¿afros? ah o sea negros, sí, pues muy poquitos, pero sí.

La entrevistadora emplea la denominación afros y el niño pregunta ¿Cómo decís? ¿afros? Y reitera ah, o sea negros. Es decir que para Manuel se trata de una cuestión en la que el color es el punto central, no el aspecto cultural o social asociado a lo afro.

Otra denominación que encontramos en las entrevistas es nigger, utilizada como marcador de grupo, de amistad: 
A: ¿Dentro de tu salón haces parte de algún grupo?

B: Pues no, de un grupo no, me hablo con la mayoría y pues me la paso con Nicolás, porque es que nos gusta lo mismo o casi lo mismo y jugamos hartas cosas y además como vivimos cerquita salimos por la tarde a jugar fútbol y así..., también salimos con Jean Pierre que también es Nigger como yo, también me cae bien Jackson y Jorge.

A: ¿Qué quiere decir nigga?

B. Pues es que así es que nos decimos entre los afros, ¿me entendés?, mejor dicho es que no es nigga es Nigger (lo escribe en un papel), así mirá y así nos decimos entre nosotros, pero los demás no nos pueden decir así, es solo entre nosotros.

Miguel señala el carácter grupal interno de la denominación "es sólo entre nosotros", si otros emplean esta denominación se convierte en ofensa.

\section{La valoración étnica}

La valoración se ubica en el campo del espacio afectivo e incluye juicios positivos o negativos hacia los individuos o grupos por el solo hecho de pertenecer a un grupo. En el grupo de niños y niñas entrevistados, las actitudes van entre un extremo y otro marcado por el orgullo o el rechazo de la condición étnica.

\section{El orgullo}

En los discursos de niños y niñas pareciera existir una correspondencia entre la autoidentificación dentro de las categorías cromáticas y las actitudes o valoraciones del color. Así quienes se clasifican como negros tienden más a valorar esta condición que quienes niegan el color y buscan otras categorizaciones étnicas menos marcadas. Aunque, de alguna manera, negar el color de la piel implícitamente implica una valoración de rechazo.

Niños y niñas parecen dar importancia a estereotipos diferentes, así los niños desde muy temprano asumen como propias y reales características que se les han atribuido a lo largo de la historia a los negros: bailar, ser buenos deportistas y ser chistosos. 
Aceptación de los estereotipos étnicos

El orgullo en ocasiones obedece a distintas causas, hay un orgullo relacionado de manera directa con los estereotipos, entendidos éstos como el conjunto de rasgos o características que se le atribuye a un grupo y sus miembros.

\begin{abstract}
A: ¿Cómo te sientes siendo afro?
B: Re-bien, soy diferente de los demás y me gusta, además siempre la gente dice que bailo y me parezco como Michael Jackson, bueno la que más lo dice es mi má.
\end{abstract}

Miguel se siente orgulloso de su condición étnica, pues ésta lo hace diferente de los demás y lo acerca al estereotipo del negro bailarín. Más adelante en la entrevista, Miguel refuerza este estereotipo al señalar que:

A: ¿Crees que la facilidad para bailar la tienes por ser afro o por qué?

B: Pues claro que sí, es porque los negros llevamos la música en la venas y hacemos muy buenos movimientos, ya hacemos cosas que los blanquitos nunca pueden hacer por más que intenten.

A: ¿Cómo que cosas hacen los negros que los blancos no?

B: Como jugar baloncesto re-bien, correr mucho, en carreras y todo, ¿no ves que siempre ganan negritos del África?, además los pasos de Michael Jackson solos pueden hacer los negros, los blancos se destortillan, (se ríe), de veras.

A: O sea que todos los que sean afros en todo el mundo tienen que bailar bien, ¿sí?

B: Pues si son negros de verdad y si no son pintados.

Reitera que es la condición de afro lo que lo hace ser bueno para el baile y además incluye otras habilidades como el deporte. De nuevo los hechos hablan por sí solos como lo evidencia su pregunta a la entrevistadora: ¿No ves que siempre ganan negritos del África? Se trata en últimas de la reproducción de las representaciones hegemónicas, producto de la dominación histórica que ha sufrido el pueblo afrodescendiente. 


\section{Negros pintados}

Miguel introduce aquí un elemento importante: la existencia de negros de verdad y negros pintados, es decir, aquellos que no satisfacen los estereotipos:
A: ¿Cómo pintados?
B: Ay, mira, es que pintados son los negros que por fuera son negros pero de verdad no hacen las cosas que hacemos los n... digo los afros, ¿ya? A: Ah o sea, por ejemplo Jaime, que no sabe bailar, ni le gusta jugar baloncesto, ¿él sería pintado?
B: Exacto, que no parecen niggas con lo que hacen y son todos aburridos así como él.

\section{Orgullo histórico}

Aunque niños y niñas no están muy familiarizados con la historia africana, en sus familias, más que en la escuela han aprendido que provienen de una raza fuerte y aguerrida que padeció muchas injusticias, eso los hace sentir orgullosos de su pasado y sus orígenes:

A: ¿Cómo te sientes en general siendo negro?, como tú dices.

B: Ah, a mí sí me gusta mucho, yo sé que descendemos de los africanos, en cambio los blancos, ni saben de donde salieron así, (ríe), no, en serio, con mi papá, yo leo de la historia de los negros de África y les tocaba re duro, eran esclavos y todo, y ellos dicen que nosotros tenemos que estudiar mucho para salir adelante y no seguir esclavizados y digamos... mi color de la piel me gusta más que así todo pálido (señala a la entrevistada y sonríe).

\section{Orgullo regional}

En ocasiones el orgullo histórico también se relaciona con un orgullo más de tipo regional en el que niños y niñas añoran sus lugares de origen en los que todos son iguales, o por lo menos iguales a ellos.
A: Jaime y ¿ese apellido de dónde es?
B: Es sobre todo de gente del Chocó... 
A: ¿Tú eres del Chocó?

B: Sí, jahh! esa es la tierra más bacana.

A: ¿Tú crees?, ¿Por qué?

B: Sí, pues ufff, claro que sí, porque... pues la gente, todos son como nosotros y nadie humilla a nadie por plata, no se tiene mucha pero apenas, se sale con los amigos al río, se sale a jugar chapas por la tarde en la calle y andamos descalzos a toda hora... (Dirige su mirada arriba), sí, muy rico. A: ¿Por qué dices que todos son como nosotros, a qué te refieres?

B: Pues negros descendientes de africanos como yo.

A: ¿Te gustaría estar con más personas de tu raza, como en el chocó?

B: Pues sí.

Esta identificación es muy importante en niños y niñas pues al remitirse a sus lugares de origen ellos sienten satisfacción y orgullo de su condición racial. Emociones positivas embargan sus discursos como en el caso de Jaime, un niño bastante tímido y aislado del grupo que, al mencionarle el Chocó, cambia su estado de ánimo, como se observa en las sucesivas exclamaciones y en el contenido de su discurso. Ronda en ellos la idea del origen, de aquel tiempo y espacio donde todos eran iguales sin distinciones de raza ni color. En ese sentido es recurrente la idea del retorno, del regreso a sus lugares de origen, diferentes a Bogotá en donde el racismo y la discriminación son el día a día de niños y niñas.

\section{EI rechazo}

\section{Rechazo por el canon de belleza}

Aunque en general niños y niñas tienen una autopercepción positiva, el género entra a jugar un papel importante. Las niñas son más susceptibles al asunto del canon de belleza que las élites han establecido históricamente como dominante: el patrón blanco igual a belleza. Bajo esta lógica, se inicia el proceso de blanqueamiento, que comienza, psicológicamente, por negar el propio color de la piel y, físicamente, por asumir características del grupo dominante tales como aclararse la piel, o alisarse el cabello.

Las niñas, desde una edad muy temprana, al entrar en contacto con los medios de comunicación y a través de las relaciones interpersonales con miembros de los grupos blancos dominantes, perciben estas lógicas, establecen relaciones de comparación, cuestionan su belleza y se sienten inferiores, como es el caso de María: 
A: ¿Me podrías describir a tu mamá?

B: Sí.

A: ¿Cómo es ella?

B: Ella es bajita, casi como yo, mmm... tiene los ojos grandes y cafés, es blanquita, tiene su cabello bonito y uñas largas... qué más... no sé... es blanquita".

A: ¿Tu mamá tiene la piel blanca?

B: Sí, (inclina su cabeza hacia abajo)

A: ¿eso te molesta?

$\mathrm{B}$ : A veces.

A: ¿Por qué?

B: Porque hay gente que cuando sabe que mi mamá es blanca o me conocen, piensan que soy adoptada o dicen cosas feas por lo que soy diferente a ella, o sea pues negra digamos...

María es una niña de 7 años, hija de padre afrodescendiente y madre blanca. Es interesante como en su relato al describir a su mamá reitera su color: "blanquita" y el aspecto de su cabello, "cabello bonito". María establece una comparación con su madre y asume que sus rasgos, al ser diferentes, la hacen fea:

A: ¿Cómo te sientes perteneciendo a la comunidad afrodescendiente?

B: Pues es que a mí me molestan por ser así y eso no me gusta, a veces me siento mal, porque las otras niñas si son todas bonitas y yo no.

A: ¿Por qué dices que no eres bonita?

B: Por mi cabello y algunos se burlan y cuando molestan a algún niño conmigo se pone bravo como si fuera un castigo, yo creo que nunca voy a tener un novio.

María asume que su condición de afrodescendiente, más específicamente por el color de su piel no es bonita como las otras niñas, y su cabello es un atenuante, como lo reitera:

A: ¿Qué dicen tus hermanos?

B: No pues el que tiene trece no dice nada y como que me ayuda a veces y me dice que le cuente cuando me molesten, pero el otro mi hermano el que tiene once años, jum... me molesta y me dice pelo de humo y pelo de loca a veces cuando estoy recién levantada, porque es que el pelo se me alborota mucho, pero yo no sé que hacer porque no es mi culpa. 
A: ¿Te gustaría tener el pelo distinto?

B: Sí, como el de mi mamá que es lisito, así Fernando no me molestaría.

El cabello liso se convierte entonces en el ideal de cabello, asociado a la belleza y a lo blanco como elemento no marcado de las relaciones interétnicas.

\section{Rechazo por la no identificación fenotípica}

Algunos niños también rechazan ser denominados afrodescendientes o negros, aunque no como las niñas por cuestiones de belleza, pero sí por los rasgos fenotípicos estereotipados que identificarían al negro. Como lo señala Jaime, en este fragmento de entrevista:
A: Tus compañeros de aquí te consideran afro, ¿sabías eso?
B: Sí, por lo que mi papá es afro, pero yo salí más a mi mamá que no lo es, pero pues no me gusta que digan que soy afro porque, mi cara no es como la de ellos...¿me entiende?, ni mi pelo tampoco.
A: No, no entiendo, ¿cómo son la cara y el pelo de los afros entonces?
B: Pues toda gorda, nariz y boca grande y el pelo todo chistoso y el mío no es así, pero a mí ellos me caen bien.
A: ¿Te molesta que te digan afro?
B: Sí, porque no entienden que parece, pero no soy afro, sólo se dejan llevar porque estoy un poquito oscuro, pero soy moreno, no negro.

Rasgos como la forma de la nariz y la boca y el tipo de cabello se constituyen en elementos identificadores y asociativos a lo negro. La escala cromática de nuevo adquiere sentido. El negro constituye el extremo negativo.

\section{Dinámicas identitarias étnicas}

Como se señaló en la teoría, las identidades son construcciones que obedecen a tensiones, contradicciones y resistencias. Empleo el término dinámicas para señalar este movimiento de ida y vuelta, para señalar la calidad de proceso antes que de estatismo, aceptación o simple asimilación. 


\section{Las relaciones interétnicas}

\section{La negación del conflicto}

Hay un elemento recurrente en las entrevistas de niños y niñas. Una doble negación, primero, una tendencia a negar los conflictos interétnicos y segundo una negación a hablar de ellos. Las temáticas de las entrevistas estuvieron orientadas inicialmente hacia la familia, y el barrio, como temas generadores de diálogo y luego se centraron en la escuela, las relaciones personales y la amistad, es decir las relaciones de grupos. La mayoría de niñas y niños, al preguntársele por la manera como comenzaron a relacionarse con el grupo de estudiantes, si tuvieron inconvenientes o no, optan por señalar que no tuvieron problemas o que no recuerdan; sin embargo, después en el dialogo introducen el conflicto casi sin darse cuenta, luego al ser interpelados se niegan a hablar de él, tienden a minimizarlo y a justificarlo.

A: ¿Alguna vez has tenido algún problema en el colegio con la gente?... ¿Te han molestado por algo?

B: No (gestual).

A: ¿Seguro?

B: No (gestual).

A: Ah... y si te molestaran por algo... ¿Por qué te molestarían?

B: Porque soy negro.

A: ¿Crees que te podrían molestar por eso?

B: Sí (gestual).

A: Y ¿por qué crees eso?

B: Porque ya lo han hecho.

A: ¿Quiénes?, cuéntame...

B: Otros niños de otros cursos, el año pasado...

A: ¿Me puedes contar qué te pasó?

B: ...

A: ¿No me quieres contar? ¿Te da miedo?

B: ...

A: Bueno, si no me quieres decir pues hablamos de otra cosa. Cuéntame, por ejemplo, qué haces en vacaciones...

B: (Suspiro) Ah... pues cosas divertidas.

En esta entrevista, Raúl niega reiteradamente haber sido molestado por sus compañeros, pero, ante la posibilidad del conflicto en términos hipotéticos planteada por la entrevistadora, señala que podrían molestarlo por ser negro, 
como en efecto le ha sucedido en ocasiones, y como sucede en otras entrevistas, al tener que reconocer el conflicto, lo ubica en el pasado, un pasado lejano que lo distancia de la crudeza de tener que aceptarlo como un hecho presente y cotidiano en la escuela. La negativa a hablar del tema es tan fuerte, que las entrevistadoras varias veces tuvieron que cambiar de tema e incluso en una ocasión constituyó en objeto de terminación de la entrevista. Veamos la secuencia:

B: Ah, Porque a mí siempre me están molestando.

A: ¿Y cómo te molestan?

B: Pues molestando.

A: ¿Y qué te dicen?

B: ... ¿A mí? Diferentes cosas.

A: Por ejemplo una:

B: ¿Una? Me dicen como negro... y eso etcétera... y entonces llegan y me dicen ... y se inventan.

A: ¿Qué se inventan?

B: Unas cosas diferentes... ¿Se acabó la entrevista?

A. Sí, ya se acabó la entrevista.

Raúl es el niño más joven, tiene 6 años, quizá por esto le cuenta más hablar del tema. Al preguntársele por los conflictos él no los niega, señala que los compañeros siempre lo están molestando por ser negro, repite el patrón de no dar detalles, de no nombrar los hechos y ante la insistencia de la entrevistadora, opta por terminar la entrevista.

\section{A mí no me molestan pero a otros sí}

Algunos niños entrevistados, a pesar de que inician negando los conflictos con los compañeros, terminan por señalar que a ellos no les ha pasado, pero a otros niños sí:

A: ¿Alguna vez te has sentido rechazado por tus otros compañeros a causa de tu etnia?

B: La verdad es que yo me llevo bien con casi todos, pero a otros compañeros sí se la hacen las niñas del salón porque empiezan: Uy no yo no me hago con ese negro, que huele feo y así, pero es mentira porque no huelen feo sino que como no tienen su grupo, se las montan, yo si como ando con Nicolás, además ya tengo mi "parchecito" entonces no 
me molestan, pero a mi si no me gusta que se la monten a los otros afros del salón pero si me meto, me la van a montar a mi también y mejor no me meto en problemas porque es que tengo un genio...

Como veremos enseguida, hay una tendencia a minimizar el conflicto al atribuirlo a las relaciones de género, en las que las niñas se convierten en tontas y esta es la causa del rechazo.

\section{Negación a hablar del conflicto}

Una vez que niños y niñas aceptan haber sido o ser molestados en la escuela, continúan el proceso de negación, resistiéndose a hablar sobre el tema y a entrar en detalles. Se trata quizá de un mecanismo de autodefensa que evita revivir episodios dolorosos. Como en el caso de Tania.

A: Tú dices que no hay racismo, que estás muy contenta en tu salón y todo, pero de todas maneras sientes que sería mejor estar sólo con morenos... B: Sí señora.

A: ¿Hay algo que te moleste en el fondo... de tu salón?

B: De mi salón... no, pues no.

A: ¿Segura?

B: Sí.

A: ¿Segurita? Acuérdate que aquí estás completamente segura. A mí en tu colegio nadie me conoce ni a ti nadie te conoce en mi universidad, así que no te preocupes.

B: ... Ah, sí, unas compañeras nuevas que llegaron, por ejemplo, a mi salón ¿sí?. A todo el mundo es tratándola mal, que... que porque es nueva, que no ha cogido el ambiente pero no porque es que ella ya llevar harto tiempo, ya va a cumplir un mes y para seguirlo tratando mal a uno pues a mí me parece que...

A: ¿Cuántas son ellas?

B: Eh... son dos: Luz Edith y Katherine, son dos niñas nuevas. Esas dos son... a todo el mundo que se le atraviese en el camino es tratándolo mal, que no se qué... un día yo también estaba jugando, y llegué y sin querer la rempujé, estábamos jugando congelados, entonces... llegó y me dijo ¡ah! ¡Quítese de acá negra! Que yo no sé qué!

Tania comienza negando el racismo hacia ella pero, después de largos silencios, termina por reconocer que algunas compañeras la tratan mal por su 
condición étnica. Los silencios son indicadores del carácter dramático y doloroso de la situación, al igual que el hecho de no responder de manera oral a las preguntas, sino asintiendo o negando con la cabeza. De igual manera, Tania se niega a referir exactamente las palabras que constituyen el insulto, y lo resume en la expresión "que yo no sé qué", la cual es recurrente en el discurso de los niños y las niñas entrevistadas.

\section{Minimización del conflicto}

Niños y niñas, una vez reconocido el conflicto, involuntariamente, tienden a minimizarlo o a justificarlo con distinto tipo de argumentos como las condiciones de género o las equivocaciones en la percepción:

A: ¿Cuando empezaste a estudiar aquí, tuviste algún problema para relacionarte por el hecho de ser afro descendiente?

B: ¿Mmm?, no sé, es que casi no me acuerdo, pero si hay unas niñas que eran todas bobas y decían que se asustaban conmigo que porque era negro, pero era por molestar y además estábamos muy pequeñitos.

A: ¿Recuerdas como te sentiste ese día?

B: sí, (agacha la cabeza), pero no me gusta acordarme...

A: ¿ósea, que no me quieres contar?

B: No pues tampoco, fue hace resto... es que como que cuando yo llegué pues era nuevo y todo y esas niñas como que nunca habían visto un negrito y apenas llegué, se quedaron como atontadas y la profesora me hizo sentar al lado de una niña y ella se puso a llorar, (sus facciones cambian a un estado aparente de tristeza)... de eso es lo que más me acuerdo porque parecía que yo le hubiera hecho algo malo y lo único que hice fue lo que la profe me dijo de sentarme al lado y después como ella hizo mero show, pues ya ninguna niña se quiso hacer conmigo y al final me sentaron con un niño... pero pues no pasa nada, normal es que las niñas son re-lloronas.

Manuel inicialmente mantiene la dinámica de negación de los entrevistados apelando al olvido, a la pérdida de la memoria, pero reconoce el hecho aunque de inmediato lo atribuye a la condición de género: de niñas bobas, y lo minimiza señalando que era por molestar y por su carácter de niños pequeños. Al ser interpelado de nuevo por la investigadora para que cuente lo ocurrido, Manuel expresa su tristeza, acompañada del gesto de bajar la cabeza y reconoce que prefiere dejar en el olvido esos recuerdos dolorosos. Sin embargo, ante la insistencia de 
la entrevistadora, accede a contarlo. Introduce una narrativa. Comienza por la ubicación temporal: sucedió en el pasado, hace resto; y paradójicamente continua con evaluaciones de tipo justificaciones: "cuando yo llegué pues era nuevo", en las que queda implícito que ser nuevo es condición de ser molestado, las famosas "primiparadas", típicas del ambiente escolar. Continua evaluando la situación, esta vez mediante discurso indirecto señalando la extrañeza de las niñas ante la presencia de lo diferente: "nunca habían visto un negrito". Introduce la acción complicante: “...y apenas llegué, se quedaron como atontadas y la profesora me hizo sentar al lado de una niña y ella se pudo a llorar”. Interrumpe la acción para introducir una evaluación en la que resalta el asombro de las niñas y luego concluye la acción, que también evalúa, esta vez, mediante gestos de tristeza, que dan el tono total a la narrativa. Continúa evaluando señalando su extrañeza ante la acción de la niña frente a una acción absolutamente cotidiana, sentarse al lado de un compañero de curso, señala que él no hizo nada malo, sólo seguir las instrucciones de la profesora, luego introduce la resolución de la narrativa al contar que la profesora lo sentó al lado de otro niño, después de que a causa del show de la niña, ninguna otra niña quisiera sentarse al lado de él. Cierra la narrativa con la coda, en la que trae la situación al presente: "no pasa nada", pero sigue evaluando al darle carácter ritual al hecho y atribuyéndole connotaciones de género: "normal, es que las niñas son todas bobas". En esta narrativa vemos cómo Manuel resta importancia a las acciones relativas al conflicto, recurriendo a la sobre evaluación que minimiza el conflicto.

Otra manera de minimizar el conflicto es atribuirlo a equivocaciones en la percepción hecho por los niños mestizos. Errores que simplemente son fáciles de resolver apelando a las diferencias en la escala cromática profundamente interiorizada:

A: ¿Alguna vez has tenido problemas con... con algunas personas?

B: No.

A: ¿Cuál crees por ejemplo, por qué razón te podrían molestar a ti en el colegio? ¿A ti te han molestado? Te dicen cosas...

B: Pues... al principio... al principio cuando yo entré en tercero me molestaban por... por el color de mi piel pero ya fui haciendo más amigos y ya....

A: $\mathrm{Y}$ ¿quiénes te molestaban al principio?

B: La mayoría de las veces eran los niños.

A: Las niñas...

B: Las niñas no.

A: Y esos niños están ahora en tu curso... de tu salón...

B: Sí. 
A: ah... ya , al principio... ¿me puedes hablar un poco del problema al principio? ¿Cómo... era?, ¿cómo te trataban o qué te decían?

B: Pues..... al principio yo creo que era por el color de mi piel.

A: Y qué color era el de tu piel.

B: Yo soy morenita.

A: Morenita...

B: Pero a mí me decían que... o sea, me decían chocolate...

A: Yaparte de eso, ¿qué te decían?

B: Me decían chocolate..., negrita y... todas esas cosas que tienen que ver (.) con los morenitos. Si no que pues (.) pues yo no me dejaba sino que les explicaba que yo no era de ese color, porque los negritos son oscuros y yo no era oscura.

Laura sigue el patrón de casi todos los y las entrevistadas, negación, reconocimiento, descripción. Fue en el pasado, por el color de la piel, morenita; negación a dar detalles, equivocación en la percepción y resolución. Para los niños y niñas el problema no es en sí la discriminación, el problema se reduce a una equivocación en los juicios: Los niños "blancos" no establecen las diferencias en el color de la piel, lo que para los niños negros es determinante.

\section{Los insultos étnicos}

\section{La categoría étnica básica como insulto}

Una vez superadas las primeras etapas de percepción de las diferencias étnicas, de formación de valoraciones de los grupos se comienzan a cristalizar las actitudes frente a los diversos grupos y a establecer argumentos de justificación. Los niños y niñas entrevistados recién están tomando conciencia de los conflictos de grupos y sus argumentos son bastante incipientes y se limitan como señalamos a la cuestión del color de la piel y otros rasgos fenotípicos. Por esta razón, al analizar los contenidos se observa el problema es el color, pero no cualquier color, el problema es el color negro, tanto así que la palabra "negro" por sí sola se carga de significados negativos y se constituye en el principal insulto étnico, en el desencadenante del conflicto.

A: ¿Qué te ha pasado?

B: eh... una compañera me trató mal - de otro curso - 
A: ¿De qué curso?, discúlpame.

B: De... quinto. Me trató mal entonces... yo no le dije nada porque si me dice algo es que yo estoy orgullosa de mi raza. No me pongo a pelear con otras personas porque tampoco le van a gustar que los trate mal... entonces yo no...

A: ¿Qué te dijo esta compañera?

B: Que... yo era una negra... que... ¿que qué? Que... que nuestra raza era... de no se qué... bueno, ahí un poco de cosas. Ya no me recuerdo. A: ¿Y eso por qué pasó o qué? ¿En qué situación o qué? Si tú... me imagino que no le estabas haciendo nada.

B: Es que resulta que es que había un concurso en el colegio de la que leyera mejor, entonces yo salí escogida de mi curso, de mi salón, entonces... a una chi... a una niña le tocó... le tocó... escogerla, entonces yo porque gané el concurso se puso a tratarme mal. Que ¡ay que por qué yo había ganado!, ¡que yo era una negra!, que yo no sé qué. Yo no le dije nada porque también a nadie le va a gustar que lo traten así.

Tania introduce una narrativa para hacer referencia, según ella, a los compañeros que la trataban mal. Introduce el contexto escolar y los personajes: ella y otra compañera; la situación: un concurso de lectura; la acción complicante: ella ganó el concurso, y la resolución: la compañera empezó a tratarla mal: que era negra. Evalúa mediante discurso indirecto: mediante la frase cajón "yo no sé qué", y continúa con la resolución en la ella se posiciona como una persona pacífica, víctima del insulto étnico. Concluye con la frase: a nadie le va a gustar que lo traten así. Sin embargo, el mal trato al que hace referencia, al menos de manera explícita, se limita al apelativo "negra".

\section{Me dicen negro}

Igual sucede con Romario, quien señala que el problema se da cuando le dicen negro:

A: ¿Y qué es lo que te dicen o qué te hacen?

B: Me dicen negro.

A: ¿Y por qué te dicen eso?

B: ... No sé.

A: ¿Y eso te ha pasado muchas veces?

B: No.

A: Antes me estabas diciendo que... ¿qué es lo que te hacen?

B: Me dicen negro. 
Los niños en estas etapas, quizá como mecanismo de defensa, reducen los problemas étnicos a la cuestión del color. Del color negro como elemento marcado. El poseedor de toda la carga negativa. Sin embargo los niños también distinguen el problema del contexto de enunciación, no es lo mismo un "negro" en boca de un amigo a negro en boca de un extraño, como lo aclara Juan:
A: ¿Qué piensas sobre los sobrenombres?
B: ¿Como un apodo?
A: Sí, alguna vez te han puesto sobrenombres tus compañeros?
$\mathrm{B}$ : Ah que pues a veces que me dicen el negro o el negrito.
A: ¿Cómo te sentiste cuando en vez de llamarte por tu nombre te llamaron negrito?
B: Pues eso me parece normal, porque lo hacen de parceros.
A: ¿Y si te llama así alguien que no sea tu parcero?
B: No aguanta, porque eso es de confianza solamente y si no es como un insulto o una grosería, ¿me entendés?

\section{Los apodos}

Los apodos constituyen otro ejemplo de insulto étnico.

A: ¿Te han puesto sobrenombres tus compañeros en alguna ocasión?

B: Unos niños, los más cansones del salón me dicen la negrita. Yo ya le he dicho a la profe y ella les dice que tienen que respetarme, no está bien que me digan negrita, ellos son cansones y yo no les digo los cansones. Y pues eh mi hermano que me dice... que morocha y pelo de humo (baja la cabeza).

A: ¿Cómo te sentiste cuando en vez de llamarte por tu nombre te llamaron negrita?

B: No me gusta que me digan así, porque mi nombre es María y a todos debemos llamar por su nombre... eso dice la pro Elvia.

Para María, el diminutivo negrita, que en ocasiones se señala como cariñoso, se convierte en molesto, en motivo de risas y burlas por parte de los compañeros. De esta manera, los diminutivos en términos pragmáticos se convierten en indicadores de trato afectuoso, pero también obedecen a formas solapadas de racismo. María reclama el derecho a tener un nombre propio como los demás niños y niñas a quienes no llaman "blancos" como ofensa. 


\section{Resistiendo los conflictos}

\section{El grupo como forma de resistencia}

Los niños y niñas entrevistados establecen formas variadas de resistir las relaciones conflictivas, o que ellos perciben como problemáticas en las relaciones grupales en la escuela. La forma más frecuente es la conformación de grupos frente a una mayoría blanca.

A: ¿Alguna vez te has sentido rechazado por tus otros compañeros a causa de tu etnia?

B: La verdad es que yo me llevo bien con casi todos, pero a otros compañeros si se la hacen las niñas del salón porque empiezan : Uy no yo no me hago con ese negro, que huele feo y así, pero es mentira porque no huelen feo si no que como no tienen su grupo, se las montan, yo sí como ando con Nicolás, además ya tengo mi "parchecito" entonces no me molestan, pero a mí si no me gusta que se la monten a los otros afros del salón pero si me meto, me la van a montar a mi también y mejor no me meto en problemas porque es que tengo un genio...

La conformación del grupo puede ser interétnica; lo importante es que el otro esté dispuesto a todo, incluso a pelear. No tener grupo es sinónimo de ser molestado. La lógica del grupo, sin embargo, no implica solidaridad étnica. Cada cual resuelve sus problemas. Incluso esta lógica se aplica a los mismos compañeros negros:

A: ¿Tienes compañeros niggers?

B: Pues claro y todos bailamos, ah menos la loca del Jaime... (se ríe)

A: ¿Por qué?

B: Porque no saber bailar no le hace honor a su raza, pero por eso es una loca, él sabe que yo digo eso, todo bien. (Reacciona ante la extrañeza de la entrevistadora)

A: ¿Y él que piensa de que le digas loca, solo por ser un afro que no sabe bailar?

B: Pues ni puede decir nada porque somos más (ríe). 
Mediante la expresión "somos más", Jackson resuelve el problema. Jaime no tiene posibilidad frente a un grupo constituido por varios niños.

\section{No tengo grupo que me defienda}

Las niñas tienen igual percepción. La carencia del grupo, originada por el rechazo de las compañeras blancas implica la total indefensión, como sucede con María:

A: ¿Alguna vez te has sentido rechazada por tus otros compañeros a causa de tu etnia?

$\mathrm{B}$ : Si, cuando llegué al colegio porque casi no tengo amigos y como las niñas del salón son todas creídas y se la pasan con otros niños o ellas tienen su grupo, no me hago con ellas, porque no me gusta como son $\mathrm{y}$ entonces me la paso sola y por eso no tengo grupo que me defienda.

\section{Me siento como un alien}

El grupo no es sólo una serie de amigos con quien hablar o jugar, es un elemento que determina la pertenencia, hacer parte de la mayoría o de las minorías. Ser extraño o igual. O ser, como lo señala esta niña, casi un alien. Alguien que no tiene un referente similar incluso dentro de su misma familia.

A: ¿Te gusta estudiar aquí?

B: Casi no me gusta porque este colegio es grande, me gustaba más la escuela.

A: ¿Por qué?

B: Porque allá si tenía amigos y porque no estudiaba con mi hermano, él no hace sino recordarme que soy negra.

A: $\measuredangle$ Y eso es algo que te moleste?

B: Pues sí.

A: ¿Por qué?

B: Porque no conozco a nadie más que sea como yo, a veces me siento como un alien o algo así... (Se ríe y mira para arriba)

A: ¿Cómo un alien?

B: Pues sí algo así, porque no hay nadie así como yo ni mi mamá, ni mi familia, ni siquiera tengo una sola compañera a la que peinen como a mí, me siento muy diferente de todas, en cambio los niños que aquí son afros si tienen su grupo y pues... 
Esta sensación de no ser como los otros también la comparte Jaime:

A: ¿Qué otras cosas malas te han hecho?

B: Pues que aquí los compañeros a veces me dicen disque negro Cirilo, por lo que soy calvo y pues por el color... creo, no sé, pero eso me enrabona. Disculpe, o sea eso no me gusta, allá en el pueblo yo era normal, aquí soy como un extraterrestre, soy distinto y aunque pensé que por lo que están Jackson, Jean Pierre y los otros, íbamos a unirnos por la raza, no, ellos están acostumbrados a todo esto y a mí no me gusta, a ellos les gusta ser los payasos del salón y yo paila con eso.

Hacer parte de la mayoría es ser normal, los otros son extraños, diferentes, extraterrestres. La diferencia no se resuelve con encontrar algunas personas semejantes a uno, pues éstas pueden optar por reforzar su identidad uniéndose a la mayoría, aceptando lo que se espera de ellos.

\section{Luchando contra los estereotipos}

Niños y niñas reaccionan de manera diferente a las relaciones interétnicas. Algunos buscan mecanismos de defensa para evitar los conflictos, aceptan los estereotipos que se les asignan, otros se resisten a ellos. Como es el caso de Jaime, quien no acepta que él tenga que comportarse como los otros niños negros, que bailan, juegan futbol o "se comportan como payasos":

A: ¿Por qué dices que son los payasos del salón?

B: Porque es así, ¿no los ha pillado?, cuando las niñas les dicen que bailen, ellos bailan, que los persiguen en un juego diciendo que ellos son los micos y ellos felices, además a mi no me gusta hacer todo eso.

A: ¿Ellos te molestan por eso?

B: Sí, es que ellos... yo no sé qué les pasa... creen que todos los afros tenemos que jugar baloncesto y bailar re-bien y a mí no me gusta bailar, ni soy chistoso, ellos son los del chiste a cada rato y se burlan de mí por no ser así y hasta inventan cosas feas...

A: ¿Qué cosas feas han inventado?

B: Que soy como raro porque solo leo y soy callado y me la paso más con las niñas.

A: Y ¿tú qué piensas de lo que dicen?

B: Que están equivocados, pero nahhh, nada puedo hacer, al fin y al 
cabo lo único que quiero es que mi papá me lleve rápido para el Chocó y olvidarme de todo... (se toma el rostro con las manos)

Jaime rechaza comportarse como los otros niños lo hacen. De una manera crítica asume que han adoptado los comportamientos que los otros les asignan para burlarse de ellos. Prefiere aislarse de ellos y unirse a las niñas, que como ya hemos visto, se les atribuye las causas del conflicto por "ser bobas". Aunque tiene claro que esta no es la solución para dejar de ser molestado.

La resistencia a los estereotipo también implica resistirse a un futuro poco esperanzador, a asumir el papel que de ellos se espera en la sociedad.

\begin{abstract}
A: ¿Con quién te identificas?
$\mathrm{B}$ : Si, más o menos me identifico más con la profe Elvia, a mí también me gustaría ser profe, no le voy a hacer caso como dice Fernando mi hermano que disque yo nací para cocinar porque soy negra, porque desde que yo estudie, nadie me quita eso, no como él que todo vago y de pronto a él si le toque vender cocadas cuando grande (se ríe).
\end{abstract}

\title{
Los chistes y la risa como formas de escape
}

A lo largo de la historia de la humanidad, la risa ha sido vista como un elemento liberador. En nuestras entrevistas, niños y niñas recurren a ella para burlarse de sí mismos, de los otros o de las situaciones.

Los chistes permiten restarle importancia a los hechos, convertir lo trágico en cómico:

A: Ah ya, ¿sabes qué significa afrodescendiente?

B: Pues que viene de África, como sus tatatatarararaabuelos, creo... eso lo hemos visto en clase y todo, hasta unos videos, pero les tocaba muy duro, es que ustedes los blanquitos les daban duro... no mentiras (se ríe), tú no.

Este niño convierte la esclavitud en algo cómico, actualiza el hecho trayéndolo al presente, involucrando a la entrevistadora, para luego, quitarle 
la responsabilidad del maltrato. En el siguiente fragmento, Jaime, frente a la cuestión de las diferencias étnicas, opta por recordar una escena de un programa de televisión, Plaza Sésamo, canta el estribillo de la escena y ríe restándole un poco el carácter de seriedad a la temática tratada:

A: ¿Te gustaría estar con más personas de tu raza, como en el chocó?

B: Pues sí

A: ¿Por qué?

B: Porque allá todos somos iguales y no lo tratan a uno mal, como acá, que uno se siente re-extraño, como: (canta) uno de nosotros no es como los otros... (ríe)

También es posible reírse de uno mismo, de sus propias afirmaciones:

A: ¿Tienes un mejor amigo o amiga en tu salón?

B: Sí, es Cristian.

A: ¿Cómo describirías tu relación con él?

B: Bien, él es muy inteligente y me ayuda (se ríe), no es que yo sea bruto (se ríe de nuevo), pero si es muy buena gente, además me respeta y eso es muy importante para mí.

Ante los implícitos que podrían quedar en la interacción, el cuestionamiento de su inteligencia, Jaime rectifica mediante la risa y la aclaración.

Los otros, los blancos, también son objeto de chistes y risas:

A: ¿Tienes un mejor amigo o amiga en tu salón?

B: Sí claro, es Nicolás, porque desde hace dos años nos hacemos juntos en el puesto y además somos los más grandes del salón.

A: ¿El es afrocolombiano?

B: No, ¡qué tal!, si Nicolás es más blanco que la leche (se ríe), no mentiras, él es... blanco y la mamá también. 


\section{Reflexiones finales}

Puesto que mi idea no es corroborar ni aplicar teorías o categorías preestablecidas, me limitaré a las voces de los sujetos niños y niñas entrevistados para a partir de los datos ahondar un poco en la complejidad del tema de las construcciones identitarias étnicas.

Comenzaré por resaltar el papel del discurso en la producción y reproducción del racismo y como recurso y estrategia de los hablantes para construir sus identidades. A partir de un repertorio de posibilidades de conversación, de temas, de interacción, de selección léxica, niños y niñas junto a las entrevistadoras comienzan a negociar sentidos, se trata de pequeñas escenificaciones en las que cada uno intenta mantener su "cara", así no siempre sea posible.

Las interpretaciones que se realizan a continuación, a modo de conclusiones, plantean una escritura diferente a la empleada hasta el momento en este artículo: intentan construir un tipo de texto narrativo en el que se recurre a la primera persona del singular, "yo", para dar cuenta de la voz de los niños y las niñas entrevistados.

\section{Las construcciones de las identidades étnicas}

Las construcciones de las identidades étnicas en los niños y niñas negros entrevistados se crean en un contexto de diferencia en el cual la mayoría hace parte de las personas blancas. El reconocimiento sensorial de la diferencia hace que el color se constituya en elemento clave de la interacción.

El negro, al ser el elemento marcado, se convierte en un elemento tabú: no se acepta, no se habla de él y por tanto no se nombra. Escapo de él a través de otras denominaciones o matizaciones del color. Niego su importancia en las relaciones interpersonales, niego los conflictos causados por él o minimizo sus efectos. Reacciono cuando lo usan para nombrarme, me ofendo, reclamo o sufro. Intento escapar a su determinismo juntándome con otros bajo la idea "de más es mejor”, enfrentando los estereotipos, afirmando mi diferencia, queriendo huir a un lugar mejor, o riéndome de él.

\section{La diferencia y la cantidad}

Yo no soy como los otros. Y en esa relación estoy básicamente en desventaja numérica. Si todos fuéramos iguales no existiría el problema. En mi lugar de origen, allí todos éramos iguales. Pero aquí soy tan solo uno, o quizá dos 
o tres, pero no más, incluso al interior de mi familia no todos somos iguales. La diferencia. Soy diferente a mi papá y a mi hermano y a mi hermana. Pero no soy negro. No entiendo por qué los otros no lo perciben. Basta con mirar. Soy moreno, moreno claro, moreno bacano, café, café suave; no negro, no soy negro. El color.

Bailo, me divierto a mí mismo, y divierto a los demás; juego futbol y me parezco a Michael Jackson. Mis ancestros eran africanos y les tocó muy duro y yo me siento orgulloso de mi pasado y de mi lugar de origen; tierra bacana, donde nadie humilla a nadie. ¡Si pudiera volver allí! No quiero ser diferente. Por qué no entienden que no soy negro, que mi cara no es como la de ellos. No quiero ser diferente. Quiero ser bonita como todas las niñas. Tener el cabello liso y la cara blanca. Y que nadie me moleste.

Aunque a mí nadie me molesta. A los otros niños sí, a mí no. Me podrían molestar por ser negro; a veces lo han hecho. El color. Me dicen esto y esto y que yo no sé qué y etcétera y me dicen... un poco de cosas, yo no me acuerdo, se me olvidó. Pero son las niñas, es que son bobas y lloran y pareciera que yo les hubiera hecho algo malo, pero no. Es el color. Aunque yo les explico que ese no es mi color, que los negritos son oscuros y yo no soy oscuro.

Me decían que yo era negra; me decían negro y a nadie le va a gustar que lo traten así. El color. También me decían chocolate y pelo de humo. No me gusta porque a todos los debemos llamar por el nombre, no por el color, yo no los llamo blanquitos.

Yo como tengo mi grupito, mi parchecito, entonces no me molestan, somos más. La cantidad. Pero las niñas no juegan conmigo porque soy negra y no soy bonita. Si yo tuviera un grupo que me defendiera. La cantidad. Frente a ellas yo me siento como un alien. Nadie es como yo. La diferencia. No tengo una sola compañera a la que peinen como yo. Me siento diferente, en cambio los niños que aquí son afro si tienen su grupo. Aquí soy como un extraterrestre, soy distinto. La diferencia.

Pensé que con los otros afros íbamos a unirnos por la raza, pero a ellos les gusta ser los payasos del salón y yo ipaila con eso! La diferencia. Cuando las niñas les dicen que bailen, ellos bailan, que los persiguen en un juego diciendo que ellos son los micos y ellos felices, además a mi no me gusta hacer todo eso. Si pudiera regresar donde nací. Donde todos son como nosotros. La cantidad. Olvidarme de todo.

A veces se siente reextraño, como que: uno de nosotros no es como los otros. ¡Es que ustedes los blanquitos son muy malos, ¡nos dan duro! No, mentiras, ¡tú no! 
Aproximación al concepto de identidades étnicas en niños y niñas

En ese sentido, entiendo con los niños y niñas las identidades étnicas como las representaciones que construye el sujeto de sí a partir de su relación con otros, diferentes por el color, y con dependencia del contexto, diferentes en cantidad.

\section{Discusión}

Las construcciones identitarias étnicas, entonces, están determinadas en estas primeras etapas de formación por la identificación de las diferencias y la sobrevaloración de las mismas. Quizá allí tendríamos que hacer un alto en el camino, no solo los niños y las niñas, sino también los adultos, los investigadores, los activistas políticos y demás actores sociales. Me pregunto si no sería mejor concentrarnos en aquellos aspectos que nos hacen semejantes unos a otros, aquello que nos hace a todos iguales en humanidad y dignidad. Dejar por un momento de marcar las diferencias y trascenderlas hacia el reconocimiento de la dignidad de los sujetos y de los pueblos, de todos.

\section{REFERENCIAS}

BRUNER, J. Life as narrative. Social Research, v. 71, n. 3, p. 691-710, 1994.

GARRIDO, A.; ÁLVARO, J. Psicología social. Madrid, McGraw Hill, 2007.

HALL, S. (Comp.). Cuestiones de identidad cultural. Buenos Aires. Amorrortu, 1996.

MOLINA, M.; A. VARGAS. La constitución de la identidad racial de niños y niñas afrocolombianos a partir del lenguaje que circula en la escuela. Monografía (Licenciatura en Pedagogía Infantil) - Universidad Distrital, 2009.

RESTREPO, E. Identidades. Planteamientos teóricos y sugerencias metodológicas para su estudio. Revista Jangwa Pana, p. 24-35, 2007. Versión electrónica: <http://www.ramwan.net/restrepo/documentos/identidades-jangwa\%20pana.pdf>. Acesso en: 10/03/2011.

SANTIESTEBAN, N. Dinámicas discursivas del racismo en Bogotá. Monografía Universidad de los Andes, 2005.

SMITH, C. Aportes a la comprensión de la identidad étnica en niños, niñas y adolescentes de grupos étnicos minoritarios. Ciencias Sociales, v. II, n. 96, junio, 2002. Versión electrónica: <http://redalyc.uaemex.mx/src/inicio/ArtPdfRed.jsp?iCve=15309606>. Acesso en: 04/05/2010. 
SOLER, S. Conductas y actitudes lingüísticas en la comunidad indígena inga. Revista Thesaurus, Bogotá, ICC, p. 911-979, 1999.

Pensar la relación. Análisis crítico del discurso y educación: el caso de la representación de indígenas y afrodescendientes en los manuales escolares de Ciencias Sociales en Colombia. Discurso y Sociedad, v. 2, n. 3, 2008. Versión electrónica: $<$ http:// www.dissoc.org/ediciones/v02n03/DS(2)Soler.html>. Acesso en: 04/05/2010.

; PARDO, N. Discurso y racismo en Colombia: Cinco siglos de invisibilidad y exclusión. En: VAN DIJK, T. (Ed.). Discurso y racismo en América latina. Barcelona: Gedisa, 2007, p. 191-227.

Texto recebido em 22 de junho de 2012.

Texto aprovado em 13 de agosto de 2012. 